\title{
How College Students' Achievement Goal Orientations Predict Their Expected Online Learning Outcome: The Mediation Roles of Self-Regulated Learning Strategies and Supportive Online Learning Behaviors
}

\author{
Yu-Chen Yeh, Oi-Man Kwok, Hsiang-Yu Chien, Noelle Wall Sweany, \\ Eunkyeng Baek, and William Alex McIntosh \\ Texas A\&M University
}

\begin{abstract}
The purpose of this study was to examine the underlying mechanism between goal orientations and academic expectation for online learners. We simultaneously studied the structural relationships among $2 \times 2$ achievement goal orientations, self-regulated learning (SRL) strategies, supportive online learning behaviors, and expected academic outcome in various online courses with 93 respondents (70 undergraduate and 23 graduate students). Specifically, we tested the mediation effects of both SRL strategies and supportive online learning behaviors on the relationship between achievement goal orientations and students' academic expectations. The results showed that two of the achievement goal orientations - mastery-approach (MAP) goals and mastery-avoidance (MAV) goals - predicted the adoption of SRL strategies and supportive online learning behaviors, which, in turn, predicted students' expected academic outcome for their online course. Specifically, students with higher MAP goals were more likely to adopt different types of SRL strategies and supportive online learning behaviors to facilitate their learning experience, which further enhanced their expectation for their academic outcome. By contrast, students with higher MAV goals were less likely to adopt SRL strategies and supportive online learning behaviors, which, in turn, led to lower grade expectations.
\end{abstract}

Keywords: $2 \times 2$ achievement goal orientations, self-regulated learning strategies, supportive online learning behaviors, expected academic outcome

Yeh, Y.-C., Kwok, O.-M., Chien, H.-Y., Sweany, N.W., Baek, E., \& McIntosh, W.A. (2019).

How college students' achievement goal orientations predict their expected online learning outcome: The mediation roles of self-regulated learning strategies and supportive online learning behaviors. Online Learning, 23(4), 23-41.

doi:10.24059/olj.v23i4.2076 


\section{How College Students' Achievement Goal Orientations Predict Their Expected Online Learning Outcome: The Mediation Roles of Self-Regulated Learning Strategies and Supportive Online Learning Behaviors}

Online learning has become a popular option for completing course requirements and pursuing a college degree. According to the 2018 report by the Babson Survey Research Group, U.S. higher education enrollment in online courses increased for the 14th straight year, reaching over 6.3 million students who had taken at least one online course in fall 2016, a 5.6\% increase from the previous year (Seaman, Allen, \& Seaman, 2018). However, the increasing trend of online learning is not without its challenges. For instance, online courses generally lead to lower completion rates (Patterson \& McFadden, 2009). That is, compared with traditional face-to-face courses, online courses require students to control and be responsible for their own learning processes because these courses provide more flexible learning environments. Not surprisingly, Liu, Gomez, and Yen (2009) pointed out that without a good understanding of online learning competencies, some students encounter difficulties in preparing themselves to take online courses and are at risk in this learning environment. Therefore, to help ensure student success in online learning environments, it is important to explore students' online learning readiness and motivational factors so that they remain engaged with the material.

Achievement goal theory has been the dominant research interest for the past three decades in terms of exploring students' motivation in academic settings (Nicholls, 1984; Pintrich, 2000a). Achievement goal theory specifies the kinds of goals that direct achievement-related behaviors (Maehr \& Zusho, 2009). As such, achievement goals examine the standards used by students to evaluate their opinions about achievement outcome (Dweck \& Leggett, 1988). Achievement goal theory seeks to understand why some people are motivated to overcome obstacles, while others give up easily or avoid trying altogether (Dweck, 1999). As online learning continues to expand in higher education, the effects of pursuing multiple goals simultaneously on learners' perceptions, use of strategies and behaviors, and achievement expectations in the online learning setting should be investigated.

Previous research has shown that achievement goals are associated with important manifestations of self-regulated learning (SRL; Adesope, Zhou, \& Nesbit, 2015; Zhou, 2013). Students' SRL involves the capacity to organize behavior guided by their goals and motivations (Lemos, 1999; Zimmerman, 2002). Individuals' motivation plays an important role in their adaptive engagement in the phases of SRL strategies, which in turn influences outcomes (Adesope et al., 2015; Kaplan, Lichtinger, \& Gorodetsky, 2009). SRL is a significant factor for success in online learning environments because learners need to set goals and manage their time effectively when participating in online courses (Broadbent \& Poon, 2015; Lynch \& Dembo, 2004).

In addition to using SRL, students must be more proactive to be successful in an online learning environment. Thus, Beaudoln, Kurtz, and Eden (2009) concluded that the key competencies for online learning success emanate from the learner's traits and behaviors, rather than from any factors inherent in the course. Similarly, Shea and Bidjerano (2010) suggested that an analysis of the active roles of online learners will contribute to our knowledge of learning in technology-mediated environments. Along the same lines, Steinkamp (2018) noted that because of a lack of organization, prioritization, and self-monitoring skills, many students struggle and fall behind or give up on their online studies. 
To make up for these shortcomings, Watkins (2015) suggested that the development of effective study skills is very important for online learners' achievement and retention. Further, some studies have employed open-ended surveys to identify which online learning techniques respondents found useful, or the researchers have summarized successful online behaviors/tips by interviewing successful online students or course instructors (Howland \& Moore, 2002; Roper, 2007). However, relatively few studies have examined the relationship between supportive online behaviors and academic expectations using a quantitative framework.

In sum, few studies have thoroughly examined how students learn online. Further, existing studies have included only some of the essential online learning factors and, therefore, have been limited in their examination of the underlying relationships among these factors. To fill this gap in the research, the present study focused on the motivational factors (e.g., the $2 \times 2$ achievement goal orientation), the actual actions that the students take during their learning (e.g., SRL strategies and supportive online behaviors), and their expected academic outcome in an online learning environment. As such, the study aims to provide a more comprehensive picture of how these crucial factors relate to each other and predict academic outcomes in an online learning environment. To that end, we proposed a three-path mediation model to examine how online learners' achievement goal orientations affect their academic expectations. Specifically, we tested SRL strategies and supportive online learning behaviors as two mediating mechanisms through which achievement goal orientations influence academic expectations in an online learning environment. We will review each of these essential online learning components in more detail below.

\section{$\mathbf{2} \times \mathbf{2}$ Achievement Goal Orientation and Online Learning}

Achievement goals are viewed in terms of the purpose or cognitive-dynamic focus of competence-relevant behavior (Elliot \& Church, 1997; Elliot \& McGregor, 2001). Compared to other learning motivation theories, achievement goal orientation more directly links learners' objective goal setting with their learning. For example, Elliot and McGregor (2001) developed a framework known as the $2 \times 2$ achievement goal framework. One dimension of this framework is definition - that is, when learners define their learning goal compared with themselves or others. If learners define their goal by comparing themselves to themselves, it is called a mastery goal. If learners define their goal by comparing themselves to their peers, it is called a performance goal. Another dimension of the $2 \times 2$ achievement goal framework is valence, which interprets competence as either positive or negative. Positive valence corresponds to an approaching success motivational orientation. Negative valence corresponds to an avoiding failure orientation.

These two dimensions lead to a $2 \times 2$ framework consisting of the following four achievement goal categories: mastery-approach (MAP), performance-approach (PAP), masteryavoidance (MAV), and performance-avoidance (PAV) goals. MAP goals highlight the need to gain as much knowledge and skill as possible for the purpose of mastering a task and developing higher self-competence. The PAP goals focus on demonstrating one's skills in comparison to other students. MAV goals involve students tending to avoid situations where they might not be able to learn the material or master the tasks. Finally, PAV goals focus on demonstrating one's skills to avoid unfavorable judgments about one's competence.

Achievement goal theory asks what goals individuals want to reach at the end of their learning. Therefore, achievement goal theory is closely connected with learners' learning strategies and behaviors and learning outcomes. For example, important learning skills, such as self- 
regulation and metacognitive ability, are associated with MAP goals (Pintrich, 2000b). Unlike MAP goals, the relationship between PAP goals and SRL is relatively unclear. For example, Kaplan and Midgley (1997) showed that they have a positive relationship, whereas Wolters, Yu, and Pintrich (1996) showed the opposite. PAV goals have a negative correlation with SRL and a positive correlation with self-handicap (Urdan \& Midgley, 2001). MAV goals are correlated with fear of failure and low self-determination (Elliot \& McGregor, 2001).

Though the relationship between achievement goal structures and learning strategies or learning outcomes have been found in traditional learning environments, these relationships are also expected to exist in online learning environments. For example, Xie and Huang (2014) noted that students with mastery goals demonstrated frequent participation in both posting and nonposting online discussion activities and reported that they had learned a great deal from the online learning activities. However, PAV goals negatively predicted students' nonposting behavior and perceived learning in online courses. Im and Kang (2019) concluded that only avoidance goals were negatively related to online participation, satisfaction, and achievement.

Based on these previous findings under different online learning scenarios, three of the four achievement goal orientations-MAP, PAP, and PAV-have been the major focus and most frequently studied, whereas the MAV goals have received the least attention to date. The present study included all four achievement goal subtypes and simultaneously investigated the effects of these goals on learners' perceptions, use of strategies, and learning expectations in the online learning environment.

\section{Self-Regulated Learning Strategies and Online Learning}

Self-regulated learning (SRL) refers to how students become "masters of their own learning processes" by employing learning strategies to help them reach their desired goals (Zimmerman, 1990). Self-regulation is the ability of learners to effectively engage in their own learning processes - metacognitively, motivationally, and behaviorally - typically resulting in higher levels of achievement (Zimmerman \& Schunk, 1989). According to Schunk (2005), "selfregulated learning is seen as a mechanism to help explain achievement differences among students and as a means to improve achievement" (p. 85).

SRL becomes particularly crucial for online learners who are likely to regulate their own learning frequently (e.g., more self-directed involvement, independently structuring the time on their own learning processes). Previous studies have found that self-regulated learners are more academically successful within an online learning environment (Yukselturk \& Bulut, 2007; Shea \& Bidjerano, 2010; Bradley, Browne, \& Kelley, 2017). Hence, the importance of examining the effect of SRL on improving online learning outcomes cannot be overstated. In this study, we focus on five SRL strategies - metacognitive skills, time management, environmental structuring, persistence, and help-seeking - that have been identified as important skills in online learning (Jansen, van Leeuwen, Janssen, Kester, \& Kalz, 2017).

Metacognition, defined as "thinking about thinking," refers to higher order mental processes involved in learning, such as self-checking and evaluating the cognitive process after the performance (Flavell, 1979; O'Neil \& Abedi, 1996). Since metacognitive skill highlights the importance of the subjective judgment of confidence in completing cognitive tasks as well as coping strategies while performing the tasks, it is a strong predictor of academic success (Bjork, Dunlosky, \& Kornell, 2013; Kruger \& Dunning, 1999). Metacognition has also been recognized 
as a valuable skill that can improve students' learning in online environments (Murphy, 2008; Tsai, 2009).

Time management is a self-management skill with a focus on arranging, organizing, scheduling, and budgeting one's time as a means of generating more work effectiveness and productivity (Aduke, 2015). Claessens, Eerde, Rutte, and Roe (2007) viewed time management as behaviors that aim to achieve effective use of time while performing certain goal-directed activities. Students who are able to manage their time effectively tend to have higher levels of achievement are less likely to drop out of an online course (Miertschin, Goodson, \& Stewart, 2015; Roblyer, 1999).

Structuring the environment relates to the ability of learners to arrange their physical setting to reduce disturbances during the learning process (Gagné, 1985). Structuring online learners' physical learning environment is crucial to avoiding distractions (e.g., finding a comfortable and regular place to study) since online learners are not required to be present in a traditional classroom at a particular time (Barnard, Paton, \& Lan, 2008; Du, 2016).

Help-seeking is a mechanism that includes behaviors such as understanding solutions and searching for academic support from others to prevent educational failure. Help-seeking behaviors benefit learners by addressing their academic challenges, improving their learning skills, and overcoming challenges (Golestaneh \& Askari, 2013). Due to a lack of physical proximity to online instructors and classmates, the use of appropriate help-seeking strategies is related to increased student engagement in online learning environments (Barnard et al., 2008; Hara \& Kling, 2000).

Finally, persistence, which refers to continuous effort despite the presence of obstacles or difficulties, has been shown to be related to the successful completion of online courses (Ayres, Cooley, \& Dunn, 1990).

\section{Supportive Online Learning Behaviors and Online Learning}

Since online learners can participate in courses at any place and time they wish, they should not only be able to plan, manage, and assess their learning processes but also independently develop their skills or behaviors to achieve their academic goals (Dabbagh \& Kitsantas, 2009). Some researchers have proposed that high-achieving students employ various behavioral strategies that may also play an important role in achieving good grades and getting the most out of an online course. For example, Roper (2007) surveyed a group of graduates from online credit-granting graduate-level degree programs with a 3.50 cumulative GPA or better. He identified seven practical tips from these students: "develop a time-management strategy," "make the most of online discussions," "use it or lose it," "make questions useful to your learning," "stay motivated," "communicate the instruction techniques that work," and "make connections with fellow students." Annamalai (2018) found that connecting with instructors is an important tip for a positive online learning outcome because not only does it make students produce knowledge rather than consume it, but seeking the instructor's help also provides scaffolding for the students. Further, according to Grabinger and Dunlap (2000), online learners need well-developed learning skills and strategies, such as goal setting, action planning, resource selection and evaluation, reflective learning, and time management. Similarly, Beaudoln et al. (2009) listed several critical elements of successful online learning, such as "self-motivation," "time management," "capacity to learn with limited support," "ability to cope with unstructured settings," and "relationships with other online learners." Morrison (2012) summarized a set of behaviors (e.g., "read the syllabus," "plan weekly study times," "ask questions," and "make connections with fellow students") that 
college students have identified as crucial to their success in completing their online courses for credit. In a similar vein, Sloan (2013) pointed out that behaviors like "having a dedicated workspace," "knowing and using resources," and "building relationships" are important for success in an online learning environment. Lytle (2013) added behaviors such as "connect with instructors early," "create a schedule," and "have a consistent workspace" as also being crucial for online learners. Finally, Mock (2015) suggested several tips for remaining successful in an online course, such as "establish a good workspace," "know your resources," "meet your peers and instructor," "manage time wisely," and "seek help when needed."

As mentioned above, these successful online behaviors were mostly derived from qualitative interviews. To date, the use of a quantitative approach to examine the same issue is sparse. To fill this gap in the literature, the present study employed a quantitative approach to examine how supportive online learning behaviors that have been frequently mentioned in the previous research ("communicate effectively with faculty and classmates," "create a schedule," "have a dedicated study space," "know your resources," and "manage your time") play a role in online learners' learning expectations.

As mentioned, the main purpose of this study was to examine the underlying learning mechanism of online learners. Specifically, we focus on how motivational factors (e.g., different types of goal orientations) and their actual online learning activities and behaviors (e.g., the adoption of different self-regulated learning strategies and supportive online learning behaviors) relate to learning outcome (e.g., expected grade). The ultimate goal is to provide a more complete understanding of how these essential online learning factors relate to each other and offer further useful information and insights not only for online learners but also for course instructors, designers, and administrators with the goal of eventually improving students' online learning experiences and outcomes.

\section{Methods}

\section{Participants and Procedure}

Participants were recruited from a large public university in Texas. Data were collected during the spring semester of 2018. Students who had registered for at least one online course were invited to participate through a recruitment email listing the online survey link created using Qualtrics. An information sheet was presented as the first page of the survey, and participants signed an online consent form to declare whether they would participate or not. Participants were informed that their decision would not affect their rights and final grades in the course. Students were also told that it would take approximately 30 minutes to complete the online survey and that those who completed the survey would receive a $\$ 5$ Amazon eGift card as compensation for their effort.

A total of 93 students made up the sample (83 female [89.2\%], 10 male [10.8\%]). Of these, 64 were White/Caucasian (68.8\% of the total sample), and 29 were non-White/Caucasian $(31.2 \%$ of the total sample). Seventy were undergraduate students ( $75.3 \%$ of the total sample) and 23 were graduate students $(24.7 \%)$. For six students (6.5\% of the total sample), this was the first time they had taken an online course; 87 students $(93.5 \%)$ had taken an online course before they participated in the current study. In addition, 78 students ( $83.9 \%$ of the total sample) studied within the College 
of Education and Human Development (CEHD), whereas 15 students (16.1\% of the total sample) studied in other various departments outside of CEHD.

\section{Instruments}

Achievement Goal Questionnaire. The 12 items of Elliot and McGregor's (2001) Achievement Goal Questionnaire (AGQ) were adopted to assess the following four types of achievement goals among participants: mastery-approach (MAP), performance-approach (PAP), mastery-avoidance (MAV), and performance-avoidance (PAV) goals. A sample item for measuring the MAP goal was, "I want to learn as much as possible from this online class"; for the PAP goal, "It is important for me to do well compared to others in this online class"; for the MAV goal, "I worry that I may not learn all that I possibly could in this online class;" and for the PAV goal, "My goal in this online class is to avoid performing poorly." Answers were given using a 7point Likert scale ranging from 1 (not at all true of me) to 7 (extremely true of me). Reliability coefficients (Cronbach's alpha) for the present data for the four subscales were $.88, .95, .83$, and .75 , respectively.

Self-Regulated Online Learning Questionnaire. The 36-item Self-Regulated Online Learning Questionnaire (SOL-Q; Jansen et al., 2017) was used to measure SRL for fully online courses, with a focus on individual learning strategies, including the following five subscales: (1) metacognitive skills (e.g., "I think about what I have learned after I finish working on this online course"); (2) time management (e.g., "I find it hard to stick to a study schedule for this online course"); (3) environmental structuring (e.g., "I know where I can study most efficiently for this online course"); (4) persistence (e.g., "Even when materials in this online course are dull and uninteresting, I manage to keep working until I finish"); and (5) help-seeking (e.g., "When I do not fully understand something, I ask other course members in this online course for ideas"). Answers were given along a 7-point scale ranging from 1 (not at all true for me) to 7 (very true for $\mathrm{me})$. Reliability coefficients for the five self-regulated online learning subscales were $.92, .63, .78$, .80 , and .87 , respectively.

Supportive online learning behaviors. Students' supportive online behaviors were measured by the following five behaviors (Roper, 2007; Morrison, 2012; Sloan, 2013; Lytle, 2013; Mock, 2015): (1) communicate effectively with faculty and classmates (e.g., making use of email, chats, forums, and other formats to communicate with fellow students and professors if they have any questions and need any clarification when taking online course); (2) create a schedule (e.g., making a to-do list of the tasks and sticking to their study plan for completing weekly online course requirement); (3) have a dedicated study space (e.g., finding a quiet place with a good Internet connection, access to power, no distractions, and availability at any time when taking online course); (4) know your resources (e.g., ensuring their computer is working well, installing any needed software, and verifying their browser is up-to-date, enabling them to focus their attention on online course materials and not be distracted by technology problems); and (5) manage your time (e.g., arranging time - and enough of it — regularly in their personal calendar to take the online course each week). Students were asked whether they had adopted each of these behaviors in their current online learning experience with two response options (yes or no). The internal consistency of these five online behaviors was evaluated using the Kuder-Richardson 20 (KR-20) coefficient because the questions were scored dichotomously. The KR-20 coefficient of these five online behaviors was .54. 
Expected academic outcome/expected grade. Students' expected grade (A or non-A) was regarded as their expected academic outcome for the online course they were taking.

\section{Results}

\section{Descriptive Statistics and Correlations Among the Variables}

As illustrated in Table 1, the means of the four achievement goal orientation subscales ranged from 4.02 to 5.67, and the means of the SRL subscales ranged from 4.17 to 5.65. Correlation results indicated statistically significant and positive associations between MAP goals and all SRL strategies, except for time management. In contrast, MAV goals were only negatively associated with persistence $(r=-.23, p<.05)$. PAP and PAV goals were uncorrelated with any of SRL strategies.

Further, the data indicated a positive association between MAP goals and communicating effectively with faculty and classmates $(r=.31, p<.001)$. Having a dedicated study space was also statistically and positively correlated with PAP goals $(r=.21, p<.05)$ but negatively correlated with MAV goals $(r=-.26, p<.05)$.

Metacognitive skills $(r=.28, p<.001)$, time management $(r=.21, p<.05)$, environmental structuring $(r=.52, p<.001)$, and persistence $(r=.29, p<.001)$ were all significantly and positively correlated with having a dedicated study space. Time management was significantly and positively correlated with the items of knowing your resources $(r=.27, p<.001)$ and managing your time $(r=.30, p<.001)$. Persistence was positively related to all supportive online learning behaviors, except for creating a schedule. Finally, help-seeking had a significant and positive association with communicating effectively with faculty and classmates $(r=.32, p<.001)$.

Expected grade was positively related to time management strategy $(r=.23, p<.05)$ and knowing your resources $(r=.32, p<.001)$. On the other hand, expected grade was negatively related to MAV goals $(r=-.27, p<.001)$. 
Table 1

Correlation Coefficients and Descriptive Statistics $(N=93)$

\begin{tabular}{|c|c|c|c|c|c|c|c|c|c|c|c|c|c|c|c|}
\hline & 1 & 2 & 3 & 4 & 5 & 6 & 7 & 8 & 9 & 10 & 11 & 12 & 13 & 14 & 15 \\
\hline 1. MAP & -- & & & & & & & & & & & & & & \\
\hline 2. PAP & $.25^{*}$ & -- & & & & & & & & & & & & & \\
\hline 3. MAV & .11 & .17 & -- & & & & & & & & & & & & \\
\hline 4. PAV & .05 & $.42 * *$ & $.51 * *$ & -- & & & & & & & & & & & \\
\hline 5. MS & $.48^{* *}$ & .03 & -.04 & -.01 & -- & & & & & & & & & & \\
\hline 6. TM & .18 & .01 & -.14 & -.05 & .14 & -- & & & & & & & & & \\
\hline 7. ES & $.36^{* *}$ & .10 & -.16 & -.01 & $.54 * *$ & $.27 * *$ & -- & & & & & & & & \\
\hline 8. PER & $.47 * *$ & .05 & $-.23^{*}$ & -.18 & $.58 * *$ & .20 & $.46^{* *}$ & -- & & & & & & & \\
\hline 9. HS & $.30 * *$ & .10 & -.03 & -.08 & $.48^{* *}$ & -.02 & $.41 * *$ & $.41^{* *}$ & -- & & & & & & \\
\hline 10. CEWF\&C & $.31^{* *}$ & .09 & .08 & -.13 & .19 & .10 & .06 & $.29 * *$ & $.32 * *$ & -- & & & & & \\
\hline 11. CAS & .03 & -.08 & .00 & .13 & .10 & .18 & .09 & .17 & .06 & -.01 & -- & & & & \\
\hline 12. HDSP & .14 & $.21^{*}$ & $-.26^{*}$ & -.10 & $.28^{* *}$ & $.21 *$ & $.52^{* *}$ & $.29 * *$ & .09 & .13 & .17 & -- & & & \\
\hline 13. KYR & .14 & .17 & -.17 & -.01 & .10 & $.27 * *$ & .10 & $.22 *$ & -.01 & .16 & .01 & $.25^{*}$ & -- & & \\
\hline 14. MYT & .11 & .06 & -.12 & .04 & .16 & $.30 * *$ & .14 & $.25^{*}$ & .11 & .08 & $.43^{* *}$ & $.21^{*}$ & $.43 * *$ & -- & \\
\hline 15. EG & .03 & .15 & $-.27 * *$ & -.17 & -.15 & $.23^{*}$ & .15 & .11 & .07 & .08 & -.05 & .13 & $.32 * *$ & .20 & -- \\
\hline Mean & 5.67 & 4.02 & 4.30 & 5.06 & 4.98 & 4.90 & 5.65 & 5.22 & 4.17 & & & & & & \\
\hline $\mathrm{SD}$ & 1.26 & 2.24 & 1.76 & 1.58 & 1.08 & 1.35 & 1.14 & 1.10 & 1.64 & & & & & & \\
\hline
\end{tabular}

Note. $\mathrm{MAP}=$ mastery-approach goals; $\mathrm{PAP}=$ performance-approach goals; $\mathrm{MAV}=$ masteryavoidance goals; PAV = performance-avoidance goals; $\mathrm{MS}=$ metacognitive skills; $\mathrm{TM}=$ time management; ES = environmental structuring; PER = persistence; HS = help-seeking; CEWF\&C $=$ communicate effectively with faculty and classmates; $\mathrm{CAS}=$ create a schedule; $\mathrm{HDSP}=$ have a dedicated study space; KYR = know your resources; MYT = manage your time; EG = expected grade.

${ }^{*} p<.05 .{ }^{* *} p<.01$. 


\section{Testing the Hypothesized Mediational Model}

Prior to testing the three-path mediation model, the measurement models of achievement goal orientation, SRL, and supportive online learning behaviors were tested. Models were analyzed by using Mplus (Version 8; Muthén \& Muthén, 1998-2018) with the weighted least square mean and standard deviation (WLSMV) estimation method. The altogether measurement model fit adequately to the data, $\chi^{2}(194, N=93)=227.136(p=.052), \operatorname{RMSEA}=.04$, and WRMR $=.75$. Furthermore, the overall three-path mediation model chi-square test and the model fit indices were $\chi^{2}(220, N=93)=256.694(p=.045), \mathrm{RMSEA}=.04$, and WRMR $=.81$, respectively, indicating that the model fit the data adequately. As shown in Figure 1, MAP goals had a positive impact on SRL strategies $(\beta=.61, p<.001)$, whereas MAV goals had a negative impact on SRL strategies $(\beta=-.30, p<.05)$. Furthermore, SRL strategies had a strong and positive effect on supportive online learning behaviors $(\beta=.72, p<.001)$. A positive and statistically significant effect was also found between supportive online learning behaviors and students' expected grade $(\beta=.40, p<$ $.05)$.

In addition, we examined all the mediated effects in the model by using both the Sobel test (1982) and the bootstrap method (Cheung, 2007). As shown in Figure 1, all the simple mediated effect estimates, $\widehat{\alpha_{1} \beta} \widehat{\alpha_{2} \beta}$ and $\widehat{\beta \gamma}$, were significant using the Sobel test $\left(\widehat{\alpha_{1} \beta}=.22, p<.001, \widehat{\alpha_{2} \beta}=\right.$ $-.11, p<.05, \widehat{\beta \gamma}=.39, p<.05$, respectively).

The overall mediated effects, $\widehat{\alpha_{1} \beta \gamma}$ and $\widehat{\alpha_{2} \beta \gamma}$, were then examined by using the bootstrap method with a $95 \%$ confidence interval (CI). The CIs of the mediated effects ranged from .004 to .339 for $\widehat{\alpha_{1} \beta \gamma}$ and from -0.244 to -0.001 for $\widehat{\alpha_{2} \beta \gamma}$. Neither of these CIs included zero, thus indicating that the overall mediated effects were statistically significant. In other words, both SRL strategies and supportive online learning behaviors were significant mediators: SRL strategies mediated the positive effect of MAP goals on the adoption of supportive online learning behaviors while the supportive online learning behaviors mediated the effect of SRL strategies on expected grade. In addition, SRL strategies mediated the negative effect of MAV goals on the use of supportive online learning behaviors, which, in turn, predicted expected grade. 
How College Students' Achievement Goal Orientations Predict Their Expected Online Learning Outcome:

The Mediation Roles of Self-Regulated Learning Strategies and Supportive Online Learning Behaviors

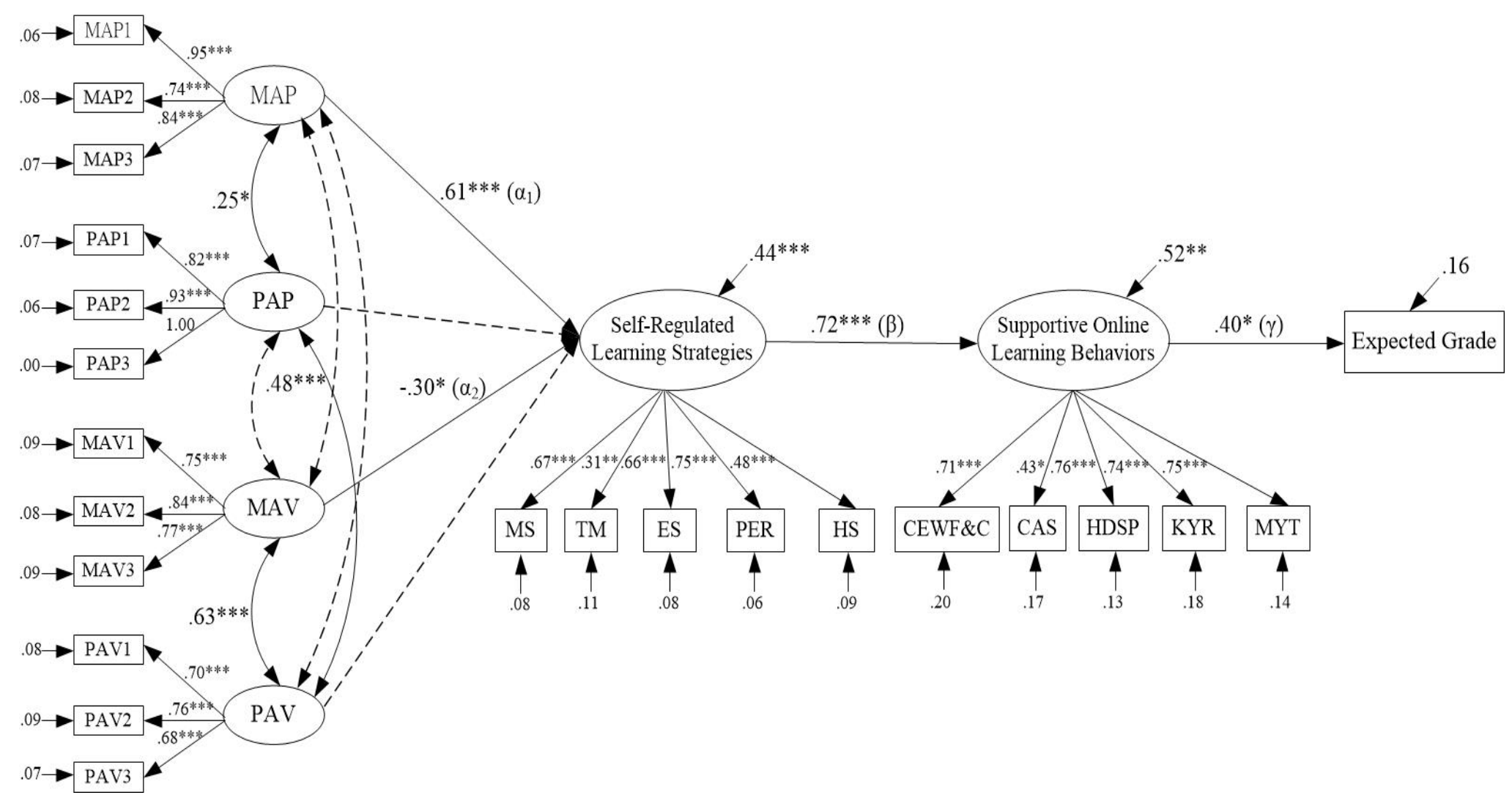

Figure 1. Three-path mediation model.

Note. All the coefficients are standardized coefficients. Dashed lines represent no significant association.

MAP = mastery-approach goals; $\mathrm{PAP}=$ performance-approach goals; $\mathrm{MAV}=$ mastery-avoidance goals; PAV = performance-avoidance goals; $\mathrm{MS}=$ metacognitive skills; $\mathrm{TM}=$ time management; $\mathrm{ES}=$ environmental structuring; $\mathrm{PER}=$ persistence; $\mathrm{HS}=$ help-seeking; $\mathrm{CEWF} \& \mathrm{C}=$ communicate effectively with faculty and classmates; CAS = create a schedule; HDSP = have a dedicated study space; $\mathrm{KYR}=$ know your resources; $\mathrm{MYT}=$ manage your time.

$* p<.05 . * * p<.01 . * * * p<.001$. 
How College Students' Achievement Goal Orientations Predict Their Expected Online Learning Outcome:

The Mediation Roles of Self-Regulated Learning Strategies and Supportive Online Learning Behaviors

\section{Discussion}

In our three-path mediation model, we proposed that the various achievement goal orientations predicted the use of SRL strategies and supportive online learning behaviors, and eventually predicted students' performance expectations. It is clear from structural equation modeling analysis that only mastery goals, including both MAP goals and MAV goals, had significant indirect effects on academic expectation via self-regulated learning strategies and supportive online learning behaviors.

This finding is consistent with those of previous studies. For example, Kaplan and Midgley (1997) discovered that mastery goals were positively related to adaptive self-regulated learning strategies. Similarly, Pintrich (2000b) reported that students who had more mastery goals had the highest likelihood of using adaptive SRL strategies than performance-goals students. Radosevich, Vaidyanathan, Yeo, and Radosevich (2004) also revealed that mastery goals were positively related to the degree to which individuals engaged in self-regulation and how many resources they allocated to their goals. In addition, our finding is in accordance with previous research suggesting that a learner with MAP goals tends to choose deep learning strategies (e.g., comparing and contrasting concepts or generating examples; Al-Emadi, 2001; Pintrich, 2000b). Learners who had strong MAP goals showed a positively significant relationship with cognitive and metacognitive learning strategies, study time and study environment managements, help-seeking behaviors, greater effort exertion and persistence, and more in-depth use of learning strategies (Howell \& Watson, 2007; Miller, Behrens, \& Greene, 1993; Sakiz, 2011; Vrugt \& Oort, 2008), which translates high commitment to high achievement (Hulleman, Schrager, Bodmann, \& Harackiewicz, 2010). Payne, Youngcourt, and Beaubien (2007) also found that the MAP goals had the strongest relationships with desirable aspects of self-regulation and performance.

On the other hand, the MAV goals construct was found to be significantly and negatively related to self-regulated learning strategies. MAV goals represent avoiding self-referential or taskreferential incompetence (Elliot, 1999). Therefore, learners with MAV goals might choose to study easier material or tend to solve only easier problems. They might also try to stick to their original learning strategies rather than create new ones to handle new types of educational settings (e.g., an online course) because they want to avoid performing worse than in prior situations or take any risk in the unknown situation. Further, some researchers found that MAV goals were linked to maladaptive cognitive and learning strategies, especially in comparison to MAP goals of striving for gains (Howell \& Watson, 2007; Van Yperen, Blaga, \& Postmes, 2015). In general, MAV goals are associated with less frequent use of SRL and more disorganized behaviors, such as attempting to minimize the effort required to complete academic tasks. Moreover, students with high MAV goals are less likely to adopt deeper processing strategies (e.g., elaboration and organizational strategies) or explore the material using different types of cognitive or thinking strategies and are likely to procrastinate, in turn resulting in lower academic performances/grades (Bernacki, Byrnes, \& Cromley, 2012; Howell \& Watson, 2007; Pintrich, 2000c).

Moreover, no indirect effects were found from both performance goals, which involve comparison with others, on academic expectations via both SRL strategies and supportive online learning behaviors. This might be because the nature of online courses offers fewer opportunities for direct comparison with peers so that students are less likely to perceive themselves as incompetent and have a lower motivation to perform better than their classmates. These nonsignificant effects are in line with previous research by Zhou and Wang (2019), who found that the effect of both PAP and PAV goals on academic performance was negative but not significant. 
Students who hold PAP or PAV goals focus more on judgments of their abilities by comparing themselves with other students and are afraid of falling behind; thus, they tend to use more superficial strategies and avoid effort utilization (Huang, 2011). Kaplan and Midgley (1997) pointed out that performance goals relate positively to maladaptive SRL strategies. Students with PAV goals prefer not to be challenged and tend to be involved in low levels of metacognitive activity (Elliot, 1999; Pintrich, Smith, Garcia, \& McKeachie, 1993). Consistent with Coutinho's (2007) study, we did not find any significant mediating effect between performance goals and academic success.

The results of the present study further support the essential role of goal setting on the adoption of SRL strategies that also have a significantly positive effect on the demonstration of supportive online learning behaviors, which, in turn, eventually lead to higher academic expectations. In other words, when students are equipped with self-regulated learning strategies, they become more active in adopting a set of supportive online learning behaviors, such as creating a schedule, managing their time, communicating with faculty and classmates during their online course, knowing their resources, and having a dedicated study space. Accordingly, students who have adopted more supportive online learning behaviors are more confident about understanding the subject matter and expect they will perform well and receive good grades at the end of the semester. According to Wandler and Imbriale (2017), self-regulated learners are likely to manage their time to complete tasks in a timely fashion without procrastination. They can also flexibly adapt or change their physical surroundings, if needed, to make them more conducive to completing their tasks.

\section{Conclusions}

Our results showed that, in an online learning environment, SRL strategies and supportive online behaviors are both important intermediaries between students' achievement goal orientations and their academic expectations. Achievement goal orientations play an important role in strengthening and promoting SRL strategies according to learners' needs. The present study revealed that students with higher MAP goals were more likely to use various types of SRL strategies, including the use of metacognitive skills, time management, environmental structuring, persistence, and help-seeking. These self-regulation strategies had a positive association with supportive online behaviors, including communicating effectively with faculty and classmates, creating a schedule, having a dedicated study space, knowing their resources, and managing their time, which, in turn, led to higher grade expectations. On the other hand, students with higher MAV goals were less likely to adopt adequate learning strategies and supportive online behaviors and had lower grade expectations in the online learning environment.

These findings provide online course instructors, designers, and even administrators, with information that allows them to create interventions tailored to students who hold MAV goals. For example, providing students with adequate resources on both SRL strategies and supportive online behaviors may contribute to students' online learning readiness, increase students' academic success expectations, and help reduce attrition rates in online courses.

A few limitations of this study warrant mention. First, our current sample $(N=93)$ could be viewed as relatively small for SEM analysis. Using the self-reported expected grade $(N=93)$ instead of actual grade $(n=64)$ as the outcome measure was to maintain a larger sample size for the analysis. Although only 64 students reported their actual final grade, the matching rate $(90.6 \%$, 
58 student matches and six student nonmatches) between the expected and the final grades for these students was shown in our study. We have also analyzed an alternative model with both actual and expected grades included in the same model as a latent factor and used the full information maximum likelihood (FIML) approach to handle the missing data. We still obtained the same pattern of significant results as the original model with this alternative model. Therefore, we felt confident using the expected grade as the academic outcome measure. Expanding the current study with additional data collection of the actual grade is another potential alternative to further validate our current model. The second limitation has to do with the cross-sectional nature of the study. A longitudinal study would have provided a better understanding of the potential causal effects across the factors we examined. In addition, future research could employ methods other than self-report in order to gather data about different achievement goals and their associations with online learning behaviors. For example, we could further employ qualitative methods to more fully explore the meaning of the different achievement goals for students with various characteristics and in different online educational settings.

\title{
Acknowledgements
}

This research was supported by a grant from the T3: Texas A\&M Triads for Transformation project.

\author{
Author Note \\ Yu-Chen Yeh, Department of Educational Psychology, Texas A\&M University \\ Oi-Man Kwok, Department of Educational Psychology, Texas A\&M University \\ Hsiang-Yu Chien, Department of Educational Psychology, Texas A\&M University \\ Noelle Wall Sweany, Department of Educational Psychology, Texas A\&M University \\ Eunkyeng Baek, Department of Educational Psychology, Texas A\&M University \\ William Alex McIntosh, Department of Sociology, Texas A\&M University
}

Correspondence concerning this article should be addressed to Oi-Man Kwok, Department of Educational Psychology, Texas A\&M University, 4225 TAMU, College Station, TX 77843-4225, or emailomkwok@tamu.edu. 
How College Students' Achievement Goal Orientations Predict Their Expected Online Learning Outcome:

The Mediation Roles of Self-Regulated Learning Strategies and Supportive Online Learning Behaviors

\section{References}

Adesope, O. O., Zhou, M. M., \& Nesbit, J. C. (2015). Achievement goal orientations and selfreported study strategies as predictors of online studying activities. Journal of Educational Computing Research, 53(3), 436-458.

Aduke, A. F. (2015). Time management and students' academic performance in higher institutions, Nigeria - A case study of Ekiti State. International Research in Education, 3(2), 1-12.

Al-Emadi, A. (2001). The relationships among achievement, goal orientation, and study strategies. Social Behavior and Personality: An International Journal, 29(8), 823-832.

Annamalai, N. (2018). How do we know what is happening in WhatsApp? A case study investigating pre-service teachers' online activity. Malaysian Journal of Learning and Instruction, 15(2), $207-225$.

Ayres, R., Cooley, E., \& Dunn, C. (1990). Self-concept, attribution and persistence in learningdisabled students. Journal of School Psychology, 28, 153-163.

Barnard, L., Paton, V., \& Lan, W. (2008). Online self-regulatory learning behaviors as a mediator in the relationship between online course perceptions with achievement. The International Review of Research in Open and Distance Learning, 9(2), 1-11.

Beaudoln, M. F., Kurtz, G., \& Eden, S. (2009). Experiences and opinions of e-learners: What works, what are the challenges, and what competencies ensure successful online learning.

Interdisciplinary Journal of E-Learning and Learning Objects, 5, 275-289.

Bernacki, M. L., Byrnes, J. P., \& Cromley, J. G. (2012). The effects of achievement goals and selfregulated learning behaviors on reading comprehension in technology-enhanced learning environments. Contemporary Educational Psychology, 37(2), 148-161.

Bjork, R. A., Dunlosky, J., \& Kornell, N. (2013). Self-regulated learning: Beliefs, techniques, and illusions. Annual Review of Psychology, 64, 417-444.

Bradley, R. L., Browne, B. L., \& Kelley, H. M. (2017). Examining the influence of self-efficacy and self-regulation in online learning. College Student Journal, 51(4), 518-530.

Broadbent, J., \& Poon, W. L. (2015). Self-regulated learning strategies \& academic achievement in online higher education learning environments: A systematic review. The Internet and Higher Education, 27, 1-13.

Cheung, M. W. L. (2007). Comparison of approaches to constructing confidence intervals for mediating effects using structural equation models. Structural Equation Modeling: A Multidisciplinary Journal, 14(2), 227-246.

Claessens, B. J. C., Eerde, W. V., Rutte, C. G., \& Roe, R. A. (2007). A review of the time management literature. Personnel Review, 36(2), 255-276.

Coutinho, S. A. (2007). The relationship between goals, metacognition, and academic success. Educate, 7(1), 39-47.

Dabbagh, N., \& Kitsantas, A. (2009). Exploring how experienced online instructors use integrative learning technologies to support self-regulated learning. International Journal of Technology in Teaching and Learning, 5(2), 154-168. 
Du, J. (2016). Predictors for Chinese students' management of study environment in online groupwork. International Journal of Experimental Educational Psychology, 36(9), 16141630.

Dweck, C. S. (1999). Essays in social psychology. Self-theories: Their role in motivation, personality, and development. New York, NY: Psychology Press.

Dweck, C. S., \& Leggett, E. L. (1988). A social-cognitive approach to motivation and personality. Psychological Review, 95, 256-273.

Elliot, A. J. (1999). Approach and avoidance motivation and achievement goals. Educational Psychologist, 34(3), 169-189.

Elliot, A. J., \& Church, M. (1997). A hierarchical model of approach and avoidance achievement motivation. Journal of Personality and Social Psychology, 72, 218-232.

Elliot, A. J., \& McGregor, H. A. (2001). A $2 \times 2$ achievement goal framework. Journal of Personality and Social Psychology, 80, 501-519.

Flavell, J. H. (1979). Metacognition and cognitive monitoring: A new area of cognitivedevelopmental inquiry. American Psychologist, 34(10), 906-911.

Gagné, R. M. (1985). The conditions of learning (4th ed.). New York, NY: Holt, Rinehart \& Winston.

Golestaneh, S. M., \& Askari, F. (2013). Help-seeking or help avoidance: Important motivational, personality and metacognitive antecedents' role in help-seeking and help-avoidance between normal and gifted students. European Online Journal of Natural and Social Sciences, 2(3), 3403-3410.

Grabinger, R. S., \& Dunlap, J. C. (2000). Rich environments for active learning: A definition. In D. Squires, G. Conole, \& G. Jacobs (Eds.), The changing face of learning technology (pp. 8-38). Cardiff, UK: University of Wales Press.

Hara, N., \& Kling, R. (2000). Students' distress with a web-based distance education course. Information, Communication \& Society, 3(4), 557-579.

Howell, A. J., \& Watson, D. C. (2007). Procrastination: Associations with achievement goal orientation and learning strategies. Personality and Individual Differences, 43(1), 167-178.

Howland, J. L., \& Moore, J. L. (2002). Student perceptions as distance learners in internet-based courses. Distance Education, 23(2), 183-195.

Huang, C. (2011). Achievement goals and achievement emotions: A meta-analysis. Educational Psychology Review, 23, 359-388.

Hulleman, C. S., Schrager, S. M., Bodmann, S. M., \& Harackiewicz, J. M. (2010). A meta-analytic review of achievement goal measures: Different labels for the same constructs or different constructs with similar labels? Psychological Bulletin, 136, 422-449.

Im, T., \& Kang, M. (2019). Structural relationships of factors which impact on learner achievement in online learning environment. International Review of Research in Open and Distributed Learning, 20(1), 111-124.

Jansen, R. S., Van Leeuwen, A., Janssen, J., Kester, L., \& Kalz, M. (2017). Validation of the selfregulated online learning questionnaire, Journal of Computing in Higher Education, 29(1), 627. 
Kaplan, A., Lichtinger, E., \& Gorodetsky, M. (2009). Achievement goal orientations and selfregulation in writing: An integrative perspective. Journal of Educational Psychology, 101, $51-69$.

Kaplan, A., \& Midgley, C. (1997). The effect of achievement goals: Does level of perceived academic competence make a difference? Contemporary Educational Psychology, 22(4), $415-435$.

Kruger, J., \& Dunning, D. (1999). Unskilled and unaware of it: How difficulties in recognizing one's own incompetence lead to inflated self-assessments. Journal of Personality and Social Psychology, 77(6), 1121-1134.

Lemos, M. S. (1999). Students' goals and self-regulation in the classroom. International Journal of Educational Research, 31, 471-485.

Liu, S. Y., Gomez, J., \& Yen, C. J. (2009). Community college online course retention and final grade: Predictability of social presence. Journal of Interactive Online Learning, 8(2), 165182.

Lynch, R., \& Dembo, M. (2004). The relationship between self-regulation and online learning in a blended learning context. International Review of Research in Open and Distance Learning, $5(2), 1-16$.

Lytle, R. (2013). 5 tips to succeed in an online course. Retrieved from https://www.usnews.com/education/online-education/articles/2013/01/14/5-tips-to-succeedin-an-online-course

Maehr, M. L., \& Zusho, A. (2009). Achievement goal theory: the past, present, and future. In K. R. Wentzel \& A. Wigfield (Eds.), Handbook of motivation at school (pp. 77-104). New York, NY: Routledge.

Miertschin, S. L., Goodson, C. E., \& Stewart, B. L. (2015). Time management skills and student performance in online courses. Paper presented at the Annual ASEE Conference \& Exposition, Seattle, WA.

Miller, R. B., Behrens, J. T., Greene, B. A., \& Newman, D. (1993). Goals and perceived ability: Impact on student valuing, self-regulation, and persistence. Contemporary Educational Psychology, 18(1), 2-14.

Mock, J. (2015). 7 tips for success when taking online courses. Retrieved from https://online.illinois.edu/articles/online-learning/item/2015/09/16/7-tips-for-online-success

Morrison, D. (2012). Five-step strategy for student success with online learning. Retrieved from https://onlinelearninginsights.wordpress.com/2012/09/28/five-step-strategy-for-studentsuccess-with-online-learning/

Murphy, E. (2008). A framework for identifying and promoting metacognitive knowledge and control in online discussants. Canadian Journal of Learning and Technology, 34(2), 9-30.

Muthén, L. K., \& Muthén, B. O. (1998-2018). Mplus user's guide (8th ed.). Los Angeles, CA: Muthén \& Muthén.

Nicholls, J. G. (1984). Achievement motivation: Conceptions of ability, subjective experience, task choice, and performance. Psychological Review, 91, 328-346.

O’Neil, H. F., Jr., \& Abedi, J. (1996). Reliability and validity of a state metacognitive inventory: Potential for alternative assessment. The Journal of Educational Research, 89(4), 234-245. 
Patterson, B., \& McFadden, C. (2009). Attrition in online and campus degree programs. Online Journal of Distance Learning Administration, 12(2). Retrieved from https://www.westga.edu/ distance/ojdla/summer122/patterson112.html

Payne, S. C., Youngcourt, S. S., \& Beaubien, J. M. (2007). A meta-analytic examination of the goal orientation nomological net. Journal of Applied Psychology, 92, 128-150.

Pintrich, P. R. (2000a). An achievement goal theory perspective on issues in motivation terminology, theory, and research. Contemporary Educational Psychology, 25(1), 92-104.

Pintrich, P. R. (2000b). Multiple goals, multiple pathways: The role of goal orientation in learning and achievement. Journal of Educational Psychology, 92, 544-555.

Pintrich, P. R. (2000c). The role of goal orientation in self-regulated learning. In M. Boekaerts, P. R. Pintrich, \& M. Zeidner (Eds.), Handbook of self-regulation (pp. 451-502). San Diego, CA: Academic Press.

Pintrich, P. R., Smith, D.A.F., Garcia, T., \& McKeachie, W. J. (1993). Reliability and predictive validity of the motivated strategies for learning questionnaire (MSLQ). Educational and Psychological Measurement, 53, 810-814.

Radosevich, D. J., Vaidyanathan, V. T., Yeo, S., \& Radosevich, D. M. (2004). Relating goalorientation to self-regulatory processes: A longitudinal field test. Contemporary Educational Psychology, 29, 207-229.

Roblyer, M. D. (1999). Is choice important is distance learning? A study of student motives for taking Internet-based courses at the high school and community college levels. Journal of Research on Computing in Education, 32(1), 157-172.

Roper, A. R. (2007). How students develop online skills. Educause Quarterly, 30(1), 62-64.

Sakiz, G. (2011). Mastery and performance approach goal orientations in relation to academic selfefficacy beliefs and academic help seeking behaviors of college students in Turkey. Educational Research, 2(1), 771-778.

Schunk, D. H. (2005). Self-regulated learning: The educational legacy of Paul R. Pintrich. Educational Psychologist, 40(2), 85-94.

Seaman, J. E., Allen, I. E., \& Seaman, J. (2018). Grade increase: Tracking distance education in the United States. Babson Survey Research Group. Retrieved from http://onlinelearningsurvey.com/reports/gradeincrease.pdf

Shea, P., \& Bidjerano, T. (2010). Learning presence: Towards a theory of self-efficacy, selfregulation, and the development of a communities of inquiry in online and blended learning environments. Computers \& Education, 55(4), 1721-1731.

Sloan, M. (2013). Tips for online learning. Principal Leadership, 52-54.

Sobel, M. E. (1982). Asymptotic confidence intervals for indirect effects in structural equation models. In S. Leinhardt (Ed.), Sociological methodology 1982 (pp. 290-312). Washington, DC: American Sociological Association.

Steinkamp, K. (2018). Four tips for a successful virtual learning initiative: How to improve student performance and prepare students for the real world by incorporating a successful online learning initiative into your school's curriculum. Tech \& Learning, 38(8), 2. 
Tsai, M. J. (2009). The model of strategic e-learning: Understanding and evaluating student elearning from metacognitive perspectives. Educational Technology and Society, 12(1), 34-48.

Urdan, T. C., \& Midgley, C. (2001). Academic self-handicapping: What we know, what more there is to learn. Educational Psychology Review, 13, 115-138.

Van Yperen, N. W., Blaga, M., \& Postmes, T. (2015). A meta-analysis of the impact of situationally induced achievement goals on task performance. Human Performance, 28(2), 165-182.

Vrugt, A., \& Oort, F. J. (2008). Metacognition, achievement goals, study strategies and academic achievement: Pathways to achievement. Metacognition and Learning, 3(2), 123-146.

Wandler, J. B., \& Imbriale, W. J. (2017). Promoting undergraduate student self-regulation in online learning environments. Online Learning, 21(2), 1-16.

Watkins, R. (2015). Building skills for e-learning success. Distance learning. Retrieved from https://onlinelearningtips.com/2015/03/building-skills-for-e-learning-success/

Wolters, C. A., Yu, S. L., \& Pintrich, P. R. (1996). The relation between goal orientation and students' motivational beliefs and self-regulated learning. Learning and Individual Differences, 8, 211-238.

Xie, K., \& Huang, K. (2014). The role of beliefs and motivation in asynchronous online learning in college-level classes. Journal of Educational Computing Research, 50(3), 315-341.

Yukselturk, E., \& Bulut, S. (2007). Predictors for student success in an online course. Educational Technology \& Society, 10(2), 71-83.

Zhou, M. (2013). Using traces to investigate self-regulatory activities: A study of self-regulation and achievement goal profiles in the context of web search for academic tasks. Journal of Cognitive Education and Psychology, 12(3), 287-305.

Zhou, Y., \& Wang, J. (2019). Goal orientation, learning strategies, and academic performance in adult distance learning. Social Behavior and Personality: An International Journal, 47(8), e8195.

Zimmerman, B. J. (1990). Self-regulated learning and academic achievement: An overview. Educational Psychologist, 25(1), 3-17.

Zimmerman, B. J. (2002). Becoming a self-regulated learner: An overview. Theory Into Practice, 41(2), 64-70.

Zimmerman, B. J., \& Schunk, D. H. (Eds.). (1989). Self-regulated learning and academic achievement: Theory, research, and practice. New York, NY: Springer-Verlag 